\title{
Evaluation efficiency of low-power fans used in the means of transport
}

The article presents test results on low-power fans used in the means of transport. Fans evaluation was in the context of energy efficiency. Interest in scientific topics related to low-power fans has its source in the reports of the Chief Inspector of Environmental Protection on the state of the natural environment in Poland and European Union reports assessing our natural environment. The goal of the article is to compare experimental results with Minister of Economy Regulation of March 11 $1^{\text {th }}, 2014$, which introduces changes in accordance to European Parliament and Council Directive 2009/125/WE, with regard to ecodesign requirements for fans driven by motors with an electric input power between $125 \mathrm{~W}$ and $500 \mathrm{~kW}$.

Key words: fans, low-power fans, evaluation efficiency, fan efficiency, transport

\section{Introduction}

This article presents the continuation of tests on lowpower centrifugal fans. Its purpose is to compare the results of tests with the Resolution of the Minister of Economy of 11 March 2014 implementing the changes in the performance of Directive 2009/125/EC of the European Parliament and of the Council with regard to ecodesign requirements for fans driven by motors with an electric input power between $125 \mathrm{~W}$ and $500 \mathrm{~kW}$.

The directive was implemented to reduce electric energy consumption as a result of technology development and improvement of the design, rising the energy efficiency of fans used for gas transportation. This Directive concerns fans driven by electric motors. For the European market in 2016 energy consumption of fans described above was 344 TWh per year. With regard to the project being implemented by the European Union, requirements for fans were established. In its main part, the Directive presents information on how to calculate the minimum energy efficiency of a fan. The formula from Directive 2009/125/EC used to determine the minimum required energy efficiency that should be obtained by a fan (driven by motor with an electric input power between $125 \mathrm{~W}$ and $10 \mathrm{~kW}$ ) is presented below:

$$
\eta=2.74 \cdot \ln \left(\mathrm{P}_{\mathrm{el}}\right)-6.33+\mathrm{N}
$$

where: $\eta$ - energy efficiency, $P_{\mathrm{el}}$ - input power of the fan, $\mathrm{N}$ - energy efficiency grade (depending on the test methodology, type of fan and the efficiency) [1].

In connection with the earlier work of the authors who researched energy boilers [2-4] and aerodynamic analysis of gas flow by recirculation [5] including the combustion chamber. The previous article [6] presents the results of testing low-power centrifugal fans, which are used in lowpower boilers

In this article presents test results on low-power centrifugal fans being a source of energy in pipeline transportation used in the means of transport.

Low-power fans are used in means of transport in ventilation, air conditioning and heaters [7]. The most commonly used air conditioners in the means of transport are integrated air conditioners installed during production, which we use in passenger cars, vans and trucks and who is part of the HVAC system (Heating, Ventilation, Air Conditioning) [8]. The integrated air conditioning system allows rising and lowering the air temperature in the vehicle's working space. Low-power fans meet the functional requirements of the project including the analysis of mass transport equations in ventilation systems, without the obligation to work with high efficiency. EU regulations impose the minimum efficiency that must be achieved by compression machines whose electrical power is greater than the defined minimum threshold given by a simple algebraic formula. As a result, almost all fans used in means of transport and mobile working machines are excluded from supervision. Compression machines are used to: increase the density of the gas medium, increase the pressure of the medium, force the flow, increase the temperature of the working medium and intensify the Joule-Thomson effect. The effect of the compression machine is to increase the pressure on the discharge side of the machine relative to the suction side. The ratio of pressure on the compressor discharge side to the pressure on the suction side is called compression. When the compression is less than 1.1 in relation to the suction side, we are talking about fans.

Figures 1-3 show selected cabin fans used to supply air to the cabin. Figure 1 presents the centrifugal fan installed in VW Jetta cars with 1.4 TSI engines with 150 HP output produced from 2014.

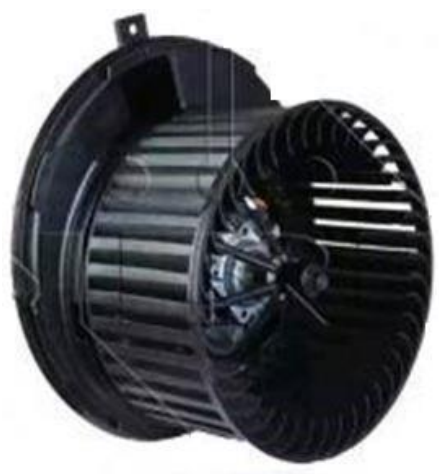

Fig. 1. Fan installed in VW Jetta [9]

Figure 2 presents the fan used in Mercedes-Benz CLS Coupe 220 BlueTEC manufactured from 2014 with $127 \mathrm{~kW}$ engine power. 


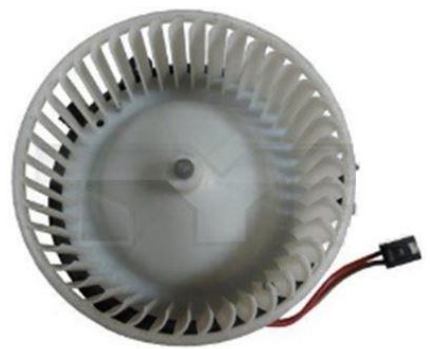

Fig. 2. Fan installed in Mercedes-Benz CLS Coupe 220 BlueTEC [9]

Figure 3 shows the fan diagram installed in the BMW 3 Series (F30 and F80) 318d produced from 2014 with a $112 \mathrm{~kW}$ engine power.

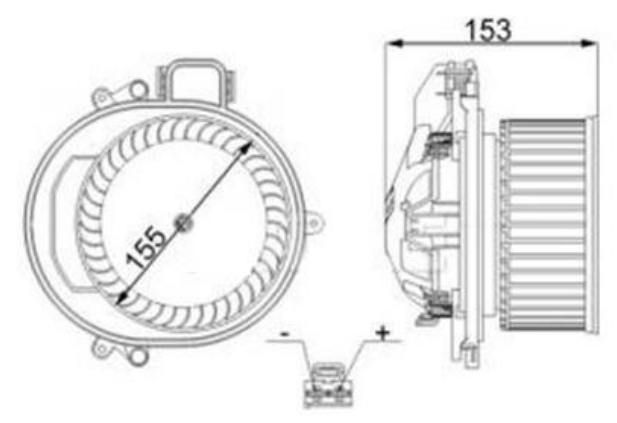

Fig. 3. Fan installed in BMW 3 Series [9]

Figures 4 and 5 show examples of fans used for cooling heat exchangers installed in various means of transport and mobile working machines. Figure 4 shows the SPAL 002B46-02 fan, which has the following parameters:

- voltage: $24 \mathrm{~V}$,

- current: $6.2 \mathrm{~A}$,

- power: $148.8 \mathrm{~W}$,

- air flow: $620 \mathrm{~m}^{3} / \mathrm{h}$.

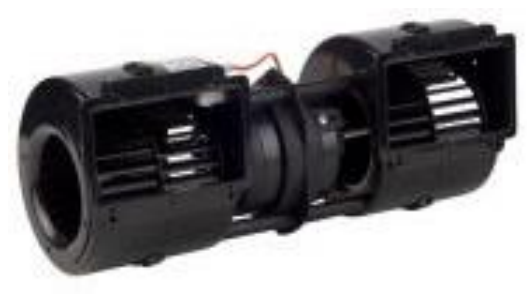

Fig. 4. Fan SPAL 002-B46-02 [10]

Figure 5 shows the SPAL 005-A45-02 fan, which has the following parameters:

- voltage: $12 \mathrm{~V}$,

- current: $13.3 \mathrm{~A}$,

- power: $160 \mathrm{~W}$,

- air flow: $610 \mathrm{~m}^{3} / \mathrm{h}$.

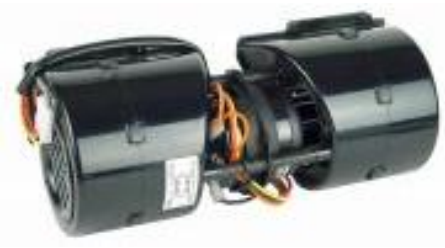

Fig. 5. Fan SPAL 005-A45-02 [10]

\section{Test method}

The subject of research were low-power fans used in transport, ventilation, air-conditioning and heaters. The fans were powered by electric motors. Nine fans with electric power from $10 \mathrm{~W}$ to $125 \mathrm{~W}$ were tested to verify the application of the directive for fans with less than $125 \mathrm{~W}$ input power.

Figure 6 presents the scheme of a measurement stand built in the Chair of Thermal Engineering of Poznan University of Technology.

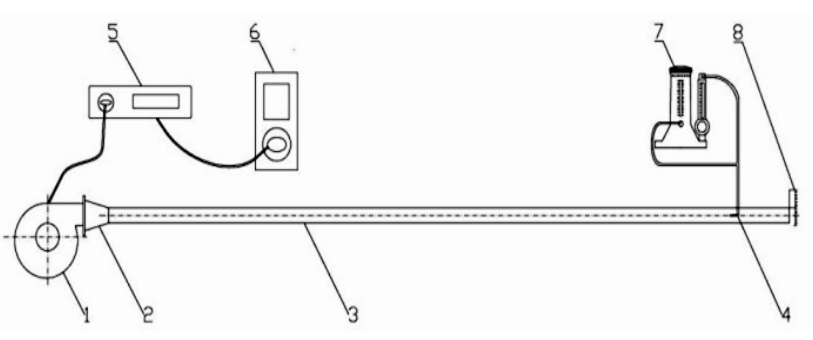

Fig. 6. Scheme of a measurement stand: 1 - fan, 2 - confusor, 3 - measuring channel, 4 - Prandtl probe, 5 - fan's operation regulator, 6 - wattmeter, 7 - compensation micro-manometer, 8 - flap valve

The measurement stand was built based on the guidelines contained in Polish standards $[11,12,13,14]$ and the directive. In the directive four measurement categories defining the arrangement of measurements and the inlet and outlet conditions of the fan were distinguished:

- "measurement category A" - the fan is measured with free inlet and outlet conditions,

- "measurement category B" - the fan is measured with free inlet and with a duct fitted to its outlet,

- "measurement category C" - the fan is measured with a duct fitted to its inlet and with free outlet conditions,

- "measurement category D" - the fan is measured with a duct fitted to its inlet and outlet.

Fans were tested using the arrangement where the fan is measured with free inlet and with a duct fitted to its outlet (measurement category B). Conducted tests allowed to measure and calculate the following quantities describing fans under tests: $\Delta \mathrm{p}_{\mathrm{c}}-$ total pressure increase, $\mathrm{P}_{\mathrm{el}}-$ electric power consumed by the fan, $\eta$ - total efficiency of the fan, $\dot{\mathrm{V}}$ - volume flow of the air flowing through the fan.

Based on the analysis of the measuring equipment used and the method of determining the characteristic parameters describing the operation of the fan, the relative error is for the following values:

- increase in total pressure $-1 \%$,

- electric power consumed by the fan $-1.5 \%$,

- air volume flow $-1 \%$.

\section{Results}

Figures from 7 to 17 present characteristics of nine fans of electric power lower than $125 \mathrm{~W}$.

Figures 7 and 8 present examples characteristics made for the fan F1 who were made for different values of motor speed $\mathrm{n}(100 \%, 72 \%$ and $45 \%$ of the maximum speed). Measurements were for relative quantities compared with the volume flow. The electric input power of the fan F1 was $37 \mathrm{~W}$. The volume flow for speeds under test was as follows: 
- for $\mathrm{n}=100 \%$, the volume flow increases from $29 \mathrm{~m}^{3} / \mathrm{h}$ to $155 \mathrm{~m}^{3} / \mathrm{h}$,

- for $\mathrm{n}=72 \%$, the pressure decreases from $29 \mathrm{~m}^{3} / \mathrm{h}$ to $106 \mathrm{~m}^{3} / \mathrm{h}$,

- for $\mathrm{n}=45 \%$, the pressure decreases from $20 \mathrm{~m}^{3} / \mathrm{h}$ to $89 \mathrm{~m}^{3} / \mathrm{h}$.

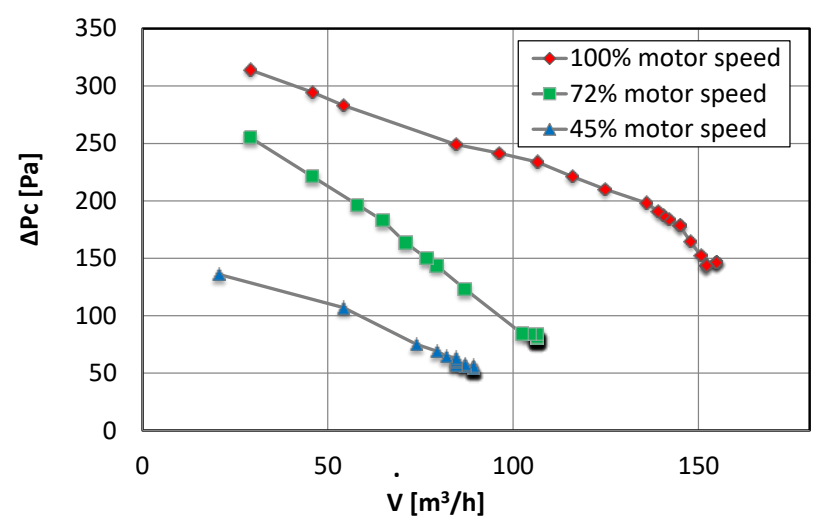

Fig. 7. Characteristics of $\Delta \mathrm{Pc}$ for fan $\mathrm{F} 1$

In Figure 7 we may notice the decrease of pressure with the increase of air volume flow. This dependence repeats for all motor speeds. For subsequent motor speeds, the pressure decrease was as follows:

- for $\mathrm{n}=100 \%$ the pressure decreased from $314 \mathrm{~Pa}$ to $147 \mathrm{~Pa}$,

- for $\mathrm{n}=72 \%$ the pressure decreased from $255 \mathrm{~Pa}$ to $80 \mathrm{~Pa}$,

- for $\mathrm{n}=45 \%$ the pressure decreased from $136 \mathrm{~Pa}$ to $54 \mathrm{~Pa}$.

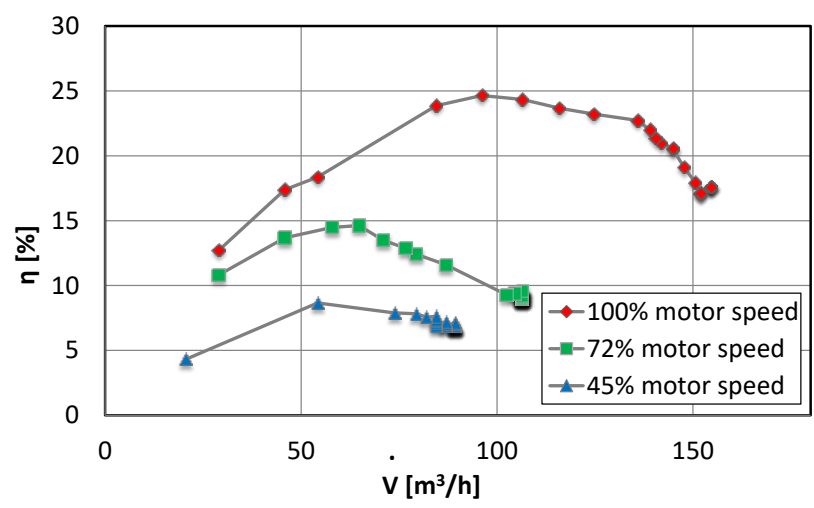

Fig. 8. Characteristics of $\eta$ for fan F1

Figure 8 presents the efficiency characteristics. The fan had the highest efficiency during testing at maximum motor speed. Efficiency for motor speed $n=100 \%$ increases with the volume flow from $13 \%$ to $25 \%$ and for the volume flow equal to $155 \mathrm{~m}^{3} / \mathrm{h}$, it starts to decrease to $18 \%$. Efficiency for motor speed $\mathrm{n}=72 \%$ increases with the volume flow from $11 \%$ to $15 \%$ and for the volume flow equal to 65 $\mathrm{m}^{3} / \mathrm{h}$, it starts to decrease to $9 \%$. Efficiency for motor speed $\mathrm{n}=45 \%$ increases with the volume flow from $4 \%$ to $9 \%$ and for the volume flow equal to $54 \mathrm{~m}^{3} / \mathrm{h}$, it starts to decrease to $7 \%$.
Figures from 9 to 17 present characteristics of total pressure increase, efficiency and power varying in a function of air volume flow. Graphs show the increase in the input electric power and the decrease in total pressure increase with the volume flow increase.

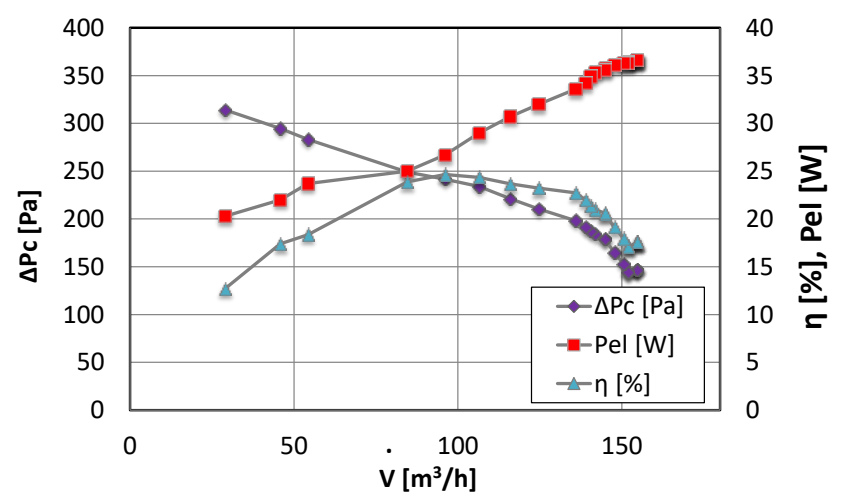

Fig. 9. Characteristics of fan F1 for $100 \%$ motor speed

Figure 9 presents the characteristics of fan $\mathrm{F} 1$ for $100 \%$ motor speed. The volume flow ranges from $29 \mathrm{~m}^{3} / \mathrm{h}$ to $155 \mathrm{~m}^{3} / \mathrm{h}$. With its increase, the pressure decreases from $314 \mathrm{~Pa}$ to $147 \mathrm{~Pa}$ and the power consumption increases from $20 \mathrm{~W}$ to $37 \mathrm{~W}$. With the increase of volume flow, the efficiency increases from $13 \%$ to $25 \%$ and for the volume flow equal to $155 \mathrm{~m}^{3} / \mathrm{h}$, it starts to decrease to $18 \%$.

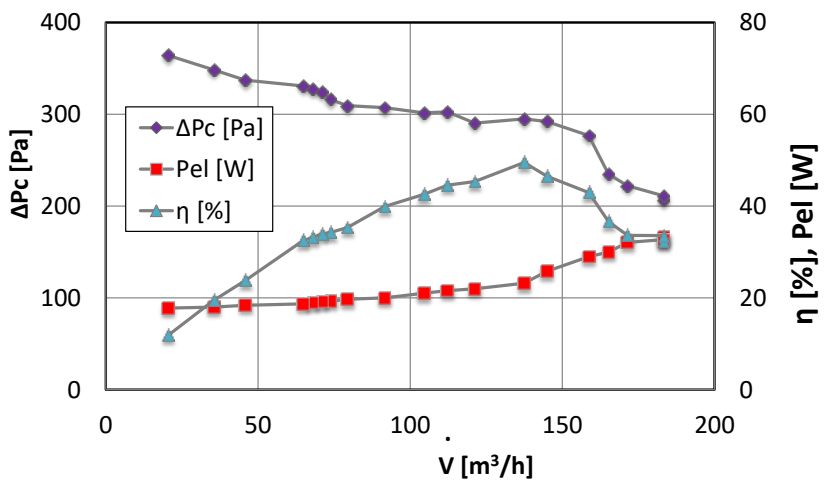

Fig. 10. Characteristics of fan F2 for $100 \%$ motor speed

Figure 10 presents the characteristics of fan $\mathrm{F} 2$ for $100 \%$ motor speed. The volume flow ranges from $20 \mathrm{~m}^{3} / \mathrm{h}$ to $183 \mathrm{~m}^{3} / \mathrm{h}$. With its increase, the pressure decreases from $364 \mathrm{~Pa}$ to $206 \mathrm{~Pa}$ and the power consumption increases from $18 \mathrm{~W}$ to $33 \mathrm{~W}$. With the increase of volume flow, the efficiency increases from $12 \%$ to $50 \%$ and for the volume flow equal to $137 \mathrm{~m}^{3} / \mathrm{h}$, it starts to decrease to $32 \%$.

Figure 11 presents the characteristics of fan F3 for $100 \%$ motor speed. The volume flow ranges from $20 \mathrm{~m}^{3} / \mathrm{h}$ to $171 \mathrm{~m}^{3} / \mathrm{h}$. With its increase, the pressure decreases from $325 \mathrm{~Pa}$ to $183 \mathrm{~Pa}$ and the power consumption increases from $18 \mathrm{~W}$ to $33 \mathrm{~W}$. With the increase of volume flow, the efficiency increases from $11 \%$ to $34 \%$ and for the volume flow equal to $130 \mathrm{~m}^{3} / \mathrm{h}$, it starts to decrease to $27 \%$. 


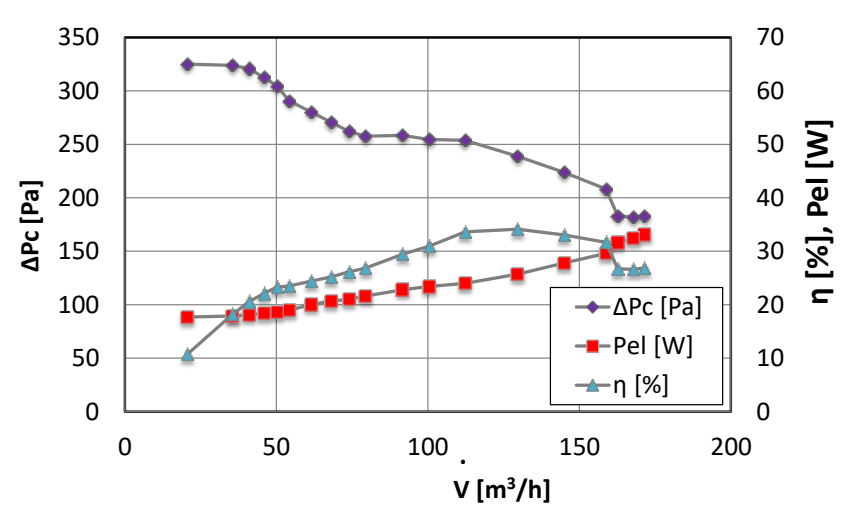

Fig. 11. Characteristics of fan F3 for $100 \%$ motor speed

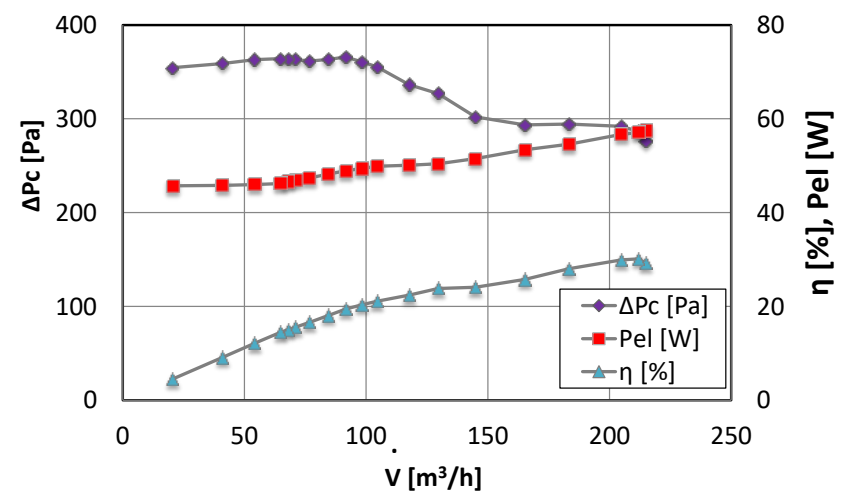

Fig. 12. Characteristics of fan F4 for $100 \%$ motor speed

Figure 12 presents the characteristics of fan $\mathrm{F} 4$ for $100 \%$ motor speed. The volume flow ranges from $20 \mathrm{~m}^{3} / \mathrm{h}$ to $215 \mathrm{~m}^{3} / \mathrm{h}$. With its increase, the pressure decreases from $354 \mathrm{~Pa}$ to $276 \mathrm{~Pa}$ and the power consumption increases from $46 \mathrm{~W}$ to $58 \mathrm{~W}$. With the increase of volume flow, the efficiency increases from $11 \%$ to $34 \%$.

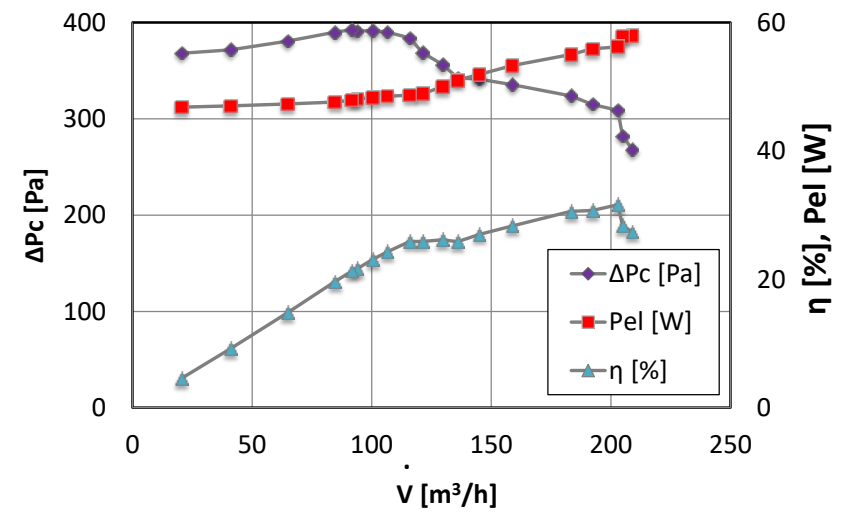

Fig. 13. Characteristics of fan F5 for $100 \%$ motor speed

Figure 13 presents the characteristics of fan F5 for $100 \%$ motor speed. The volume flow ranges from $20 \mathrm{~m}^{3} / \mathrm{h}$ to $209 \mathrm{~m}^{3} / \mathrm{h}$. With its increase, the pressure decreases from $368 \mathrm{~Pa}$ to $268 \mathrm{~Pa}$ and the power consumption increases from $47 \mathrm{~W}$ to $58 \mathrm{~W}$. With the increase of volume flow, the efficiency increases from $5 \%$ to $32 \%$.

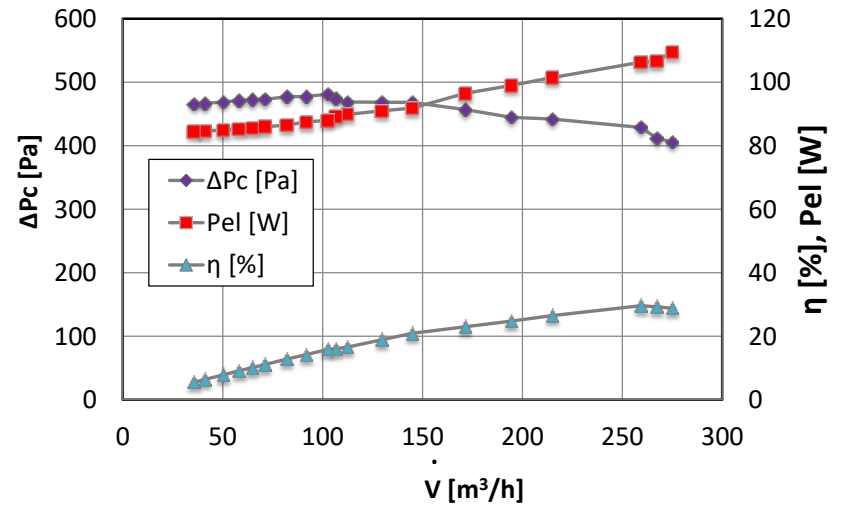

Fig. 14. Characteristics of fan F6 for $100 \%$ motor speed

Figure 14 presents the characteristics of fan F6 for $100 \%$ motor speed. The volume flow ranges from $35 \mathrm{~m}^{3} / \mathrm{h}$ to $275 \mathrm{~m}^{3} / \mathrm{h}$. With its increase, the pressure decreases from $466 \mathrm{~Pa}$ to $406 \mathrm{~Pa}$ and the power consumption increases from $85 \mathrm{~W}$ to $110 \mathrm{~W}$. With the increase of volume flow, the efficiency increases from $6 \%$ to $30 \%$.

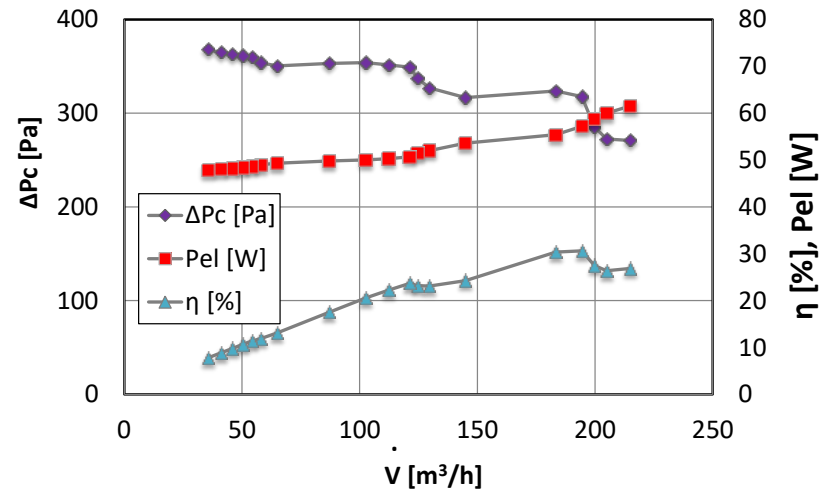

Fig. 15. Characteristics of fan F7 for $100 \%$ motor speed

Figure 15 presents the characteristics of fan F7 for $100 \%$ motor speed. The volume flow ranges from $35 \mathrm{~m}^{3} / \mathrm{h}$ to $215 \mathrm{~m}^{3} / \mathrm{h}$. With its increase, the pressure decreases from $368 \mathrm{~Pa}$ to $271 \mathrm{~Pa}$ and the power consumption increases from $48 \mathrm{~W}$ to $62 \mathrm{~W}$. With the increase of volume flow, the efficiency increases from $8 \%$ to $31 \%$ and for the volume flow equal to $194 \mathrm{~m}^{3} / \mathrm{h}$, it starts to decrease to $26 \%$.

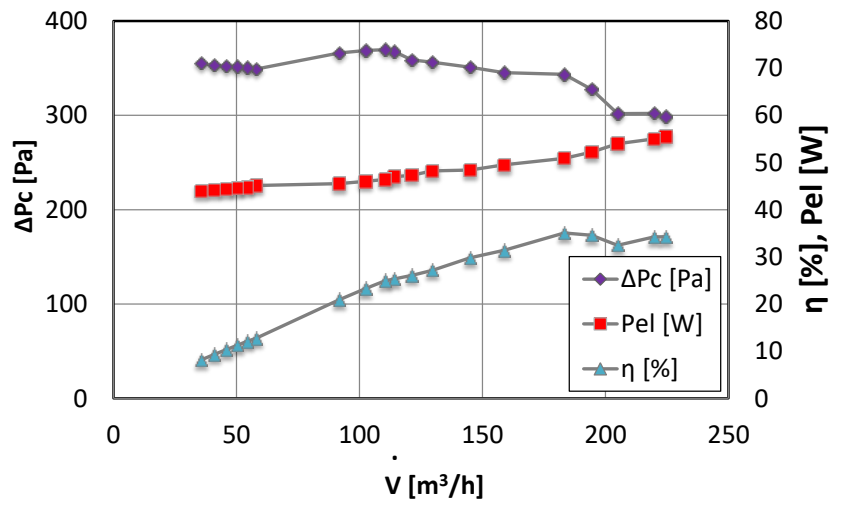

Fig. 16. Characteristics of fan F8 for $100 \%$ motor speed 
Figure 16 presents the characteristics of fan F8 for $100 \%$ motor speed. The volume flow ranges from $35 \mathrm{~m}^{3} / \mathrm{h}$ to $224 \mathrm{~m}^{3} / \mathrm{h}$. With its increase, the pressure decreases from $355 \mathrm{~Pa}$ to $299 \mathrm{~Pa}$ and the power consumption increases from $44 \mathrm{~W}$ to $56 \mathrm{~W}$. With the increase of volume flow, the efficiency increases from $8 \%$ to $34 \%$

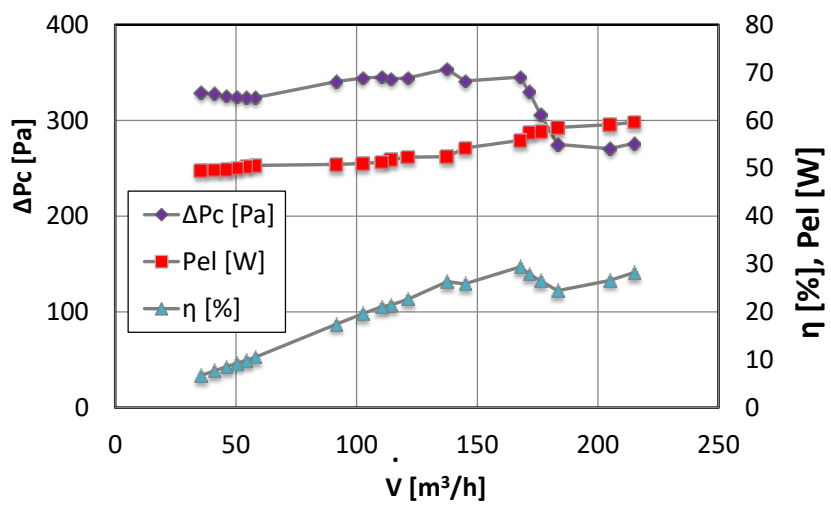

Fig. 17. Characteristics of fan F9 for $100 \%$ motor speed

Figure 17 presents the characteristics of fan F9 for $100 \%$ motor speed. The volume flow ranges from $35 \mathrm{~m}^{3} / \mathrm{h}$ to $215 \mathrm{~m}^{3} / \mathrm{h}$. With its increase, the pressure decreases from $329 \mathrm{~Pa}$ to $276 \mathrm{~Pa}$ and the power consumption increases from $50 \mathrm{~W}$ to $60 \mathrm{~W}$. With the increase of volume flow, the efficiency increases from $7 \%$ to $29 \%$.

\section{Conclusions}

Table 1 presents a comparison of the following technical parameters fans: electric power consumed by the fan, total pressure increase, volume flow of the air flowing through the fan, total efficiency of the fan.

Table 1. Comparison of technical parameters fans

\begin{tabular}{|c|c|c|c|c|}
\hline $\begin{array}{c}\text { Fan } \\
\text { symbol }\end{array}$ & $\begin{array}{c}\text { Electric } \\
\text { power } \\
\mathrm{P}_{\mathrm{el}}[\mathrm{W}]\end{array}$ & $\begin{array}{c}\text { Total pres- } \\
\text { sure increase } \\
\Delta \mathrm{Pc}[\mathrm{Pa}]\end{array}$ & $\begin{array}{c}\text { Volume flow } \\
\text { of the air } \\
\dot{\mathrm{V}}\left[\mathrm{m}^{3} / \mathrm{h}\right]\end{array}$ & $\begin{array}{c}\text { Efficiency } \\
\eta[\%]\end{array}$ \\
\hline F1 & 37 & 314 & 155 & 25 \\
\hline F2 & 33 & 364 & 183 & 50 \\
\hline F3 & 33 & 325 & 171 & 34 \\
\hline F4 & 58 & 366 & 215 & 30 \\
\hline F5 & 58 & 392 & 209 & 32 \\
\hline F6 & 110 & 481 & 275 & 30 \\
\hline F7 & 62 & 368 & 215 & 31 \\
\hline F8 & 56 & 370 & 224 & 35 \\
\hline F9 & 60 & 354 & 215 & 29 \\
\hline
\end{tabular}

Table 2 presents a summary of the results for electrical power and fan efficiency.

Figure 18 shows a comparison of the efficiency obtained as a result of test measurements and the efficiency calculated on the basis of the formula in the directive.
Table 2. Summary of results for fans' efficiencies

\begin{tabular}{|c|c|c|c|}
\hline $\begin{array}{c}\text { Fan } \\
\text { symbol }\end{array}$ & $\begin{array}{c}\text { Electric } \\
\text { power } \\
\mathrm{P}_{\mathrm{el}}[\mathrm{W}]\end{array}$ & $\begin{array}{c}\text { Efficiency } \\
\text { obtained in test } \\
\eta_{1}[\%]\end{array}$ & $\begin{array}{c}\text { Efficiency calculated } \\
\text { based on the Directive } \\
\eta_{2}[\%]\end{array}$ \\
\hline F1 & 37 & 25 & 46 \\
\hline F2 & 33 & 50 & 45 \\
\hline F3 & 33 & 34 & 45 \\
\hline F4 & 58 & 30 & 47 \\
\hline F5 & 58 & 32 & 47 \\
\hline F6 & 110 & 30 & 49 \\
\hline F7 & 62 & 31 & 47 \\
\hline F8 & 56 & 35 & 47 \\
\hline F9 & 60 & 29 & 47 \\
\hline
\end{tabular}

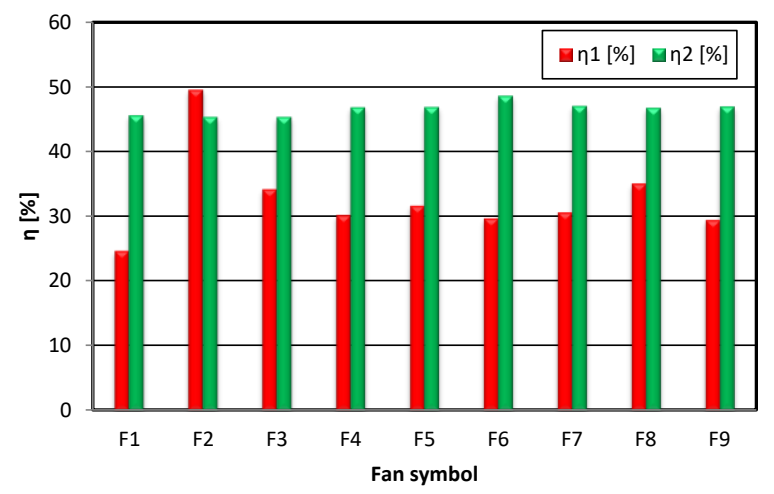

Fig. 18. Comparison results of the evaluation of efficiency

The purpose of the continuation of research in this article was to compare the results of research on nine centrifugal fans used in means of transport in terms of efficiency achieved and the requirements of the Regulation of the Minister of Economy of 11 March 2014 introducing changes in performance Directive 2009/125/EC of the European Parliament and of the Council [1] regarding ecodesign requirements for fans driven by motor with an electrical input between $125 \mathrm{~W}$ and $500 \mathrm{~kW}$. After testing the nine fans, we can see that only one fan with the F2 symbol would meet the minimum energy efficiency requirements described in the directive. The other eight do not meet the requirements. Therefore, an appropriate resolution should be prepared covering the requirements for fans of this class, based on the results of tests on already existing fans, and it is justified to formulate an application to the Polish Committee for Standardization in order to verify the abovementioned resolution. The results obtained indicate that there is a need to develop new guidelines. They should relate to the performance of low power fans with less than $125 \mathrm{~W}$ input power that is not covered by European Parliament Directive 2009/125/EC.

\section{Acknowledgements}

This work was supported by the 0712/SBAD/5148.

\section{Nomenclature}

$\eta \quad$ energy efficiency

$\mathrm{P}_{\mathrm{el}} \quad$ input power of the fan

$\mathrm{N}$ energy efficiency grade
$\Delta \mathrm{Pc} \quad$ total pressure increase

$\dot{V} \quad$ volume flow of the air 


\section{Bibliography}

[1] Commission Regulation of the European Union No. 327/2011.

[2] URBANIAK, R., BARTOSZEWICZ, J., KŁOSOWIAK, R. et al. Main causes of $\mathrm{NO}_{\mathrm{x}}$ emissions by low-power boilers. Polish Journal of Environmental Studies. 2015, 24(5), 2223 2230. https://doi.org/10.15244/pjoes/40938

[3] NYGARD, A., BARTOSZEWICZ, J., BIEŃCZAK, K. Identyfikacja nieprawidłowej eksploatacji kotłów na paliwo stałe. Przemyst chemiczny. 2019, 98(8), 1281-1282. https://doi.org/10.15199/62.2019.8.14

[4] KOCZYK, H. Heating technology practice. SYSTHERM. Poznan 2009.

[5] BARTOSZEWICZ, J., KŁOSOWIAK, R., BOGUSŁAWSKI, L. The analysis of the flow structure in a jet at variable geometry of the reverse chamber. International Journal of Heat and Mass Transfer. 2012, 11, 3239-3245.

https://doi.org/10.1016/j.ijheatmasstransfer.2012.02.050

\footnotetext{
Adam Nygard, MEng. - Institute of Thermal Energy,

Poznan University of Technology.

e-mail: adam.nygard@put.poznan.pl
}

[6] BARTOSZEWICZ, J., NYGARD, A., URBANIAK, R. Characteristics of fans used in low-power boilers. Journal of Power Technologies. 2017, 97(1), 69-74.

[7] FORTUNA, S. Fans. The Publishing house of AGH. Krakow 1999.

[8] FODEMSKI, T. Thermal measurements. part I and II, WNT, Warsaw 2006.

[9] EUautoczęści. [online] www.euautoczesci.pl/katalogczesci/ogrzewanie_wentylacja, accessed: 04.06.2020

[10] SPAL Automotive USA. [online] www.spalusa.com/products/fans, accessed: 04.06.2020

[11] Polish standard No. PN-81/M-42367.

[12] Polish standard No. PN-M-43011.

[13] Polish standard No. PN-93/M-53950/01.

[14] Polish standard No. PN-81/M-42366.

Prof. Jarosław Bartoszewicz, DSc., DEng. - Institute of Thermal Energy, Poznan University of Technology.

e-mail: jaroslaw.bartoszewicz@put.poznan.pl

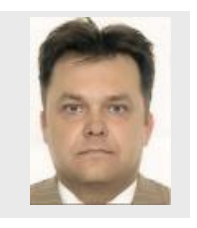

